\title{
The Impact Behavior of Composite Sandwich Used in Ship Structures
}

\author{
by Y. J. Lee*, Member H. J. Lin**, \\ Y. Shyu***
}

Summary

The impact behavior of composite sandwich panels subjected to a cylindrical impactor is investigated numerically and experimentally. Three kinds of facesheets and two different core densities of sandwich panels are considered in the impact analysis. During the experiment, the impact force and strain history are measured, and the failure is inspected by visual observations. The experimental results show that the impact behavior is mainly controlled by core material. The ABAQUS finite element software is used to analyze the impact responses of sandwich panels. Because of line load conditions, the sandwich panels impacted by the cylindrical impactor is modeled as a 2-D plane strain problem. The numerical results of impact force and strain history are compared with those measured in experiment, it is shown that the experimental results are in good agreement with the finite element solutions. Further, the stresses of sandwich panels are examined. The maximum stress failure criterion is used to estimate the fracture initiation of sandwich panels. Then the experimental and numerical results are compared and discussed.

\section{Introduction}

Owing to the advantages of lightweight, high bending strength, the composite sandwich materials play an important role in today's industry. In marine engineering, more and more ships of small sizes such as fishing boats, yachts, etc., use sandwich panels in ship hull construction. However, inadvertent collision during the fabrication process, wave impact during sailing, etc., may induce damage of sandwich structures, and cause significant reduction of the stiffness and strength of materials. Thus, further understanding of impact loading, impact response and impact damage of composite sandwich is necessary for the sake of safety.

Much work has been done on impact resistance and impact tolerance of composite sandwich panels ${ }^{1)-3}$. However, because of the complication of impact behavior, it is very difficult to predict the impact behavior of sandwich panel by establishing mathematical model or

* Professor of Institute of Naval Arch. and Ocean Eng., National Taiwan University, Taipei, Taiwan.

** Associate Professor of Institute of Naval Arch. and Ocean Eng., National Taiwan University, Taipei, Taiwan.

*** Master Student of Institute of Naval Arch.and Ocean Eng., National Taiwan University, Taipei, Taiwan.

Received 9th July 1993

Read at the Autumn meeting 9,10th Nov. 1993 by numerical analyses. Since the impact force is unknown, and is a function of many parameters including geometry of impactor, material properties of panels, impact velocity, etc., many of methods used to determine the impact force make use of some form of the Hertz method, which is derived based on homogeneous isotropic materials. However, due to the microscopic heterogeneous and anisotropic properties of composite materials, the Hertz contact law is not adequate in the analysis of contact between the projectile and composite sandwich.

An approach considered for determining the impact response of sandwich panel is to measure the local contact behavior of the panel by static indentation test. Then, using this experimental results in conjuction with impact analytical model such like the procedure used by Tan and Sun ${ }^{4}$. This approach, however, could not be regarded as true prediction since it requires fabrication of the entire sandwich and indentation tests must be made for every impactor under consideration. The true prediction should be the ability to predict the impact response of sandwich panel from a knowledge of behavior of the individual components of the sandwich panels ${ }^{3)}$

The objective of this study is to investigate the impact behavior of sandwich panels used in ship structures, subjected to a cylindrical impactor under low impact velocity. Six kinds of sandwich panels made of - various fabric-laminate and core densities were considered. Impact responses, including impact force and strain histories were measured and compared with the 
numerical results. Also, failure mode of specimen observed in the experiments were discussed. Finally, numerical stress analysis was conducted to find the stress distribution over the whole sandwich panel, then the estimation of fracture initiation can be obtained.

\section{Experiment}

\section{1 Specimen}

The facesheet of sandwich panels were made of a variety of plain-woven fabrics as specified in Table 1. Three laminated facesheets MAM, MCM, MRM (M : glass mat; $\mathrm{C}$ : carbon; $\mathrm{R}$ : glass roving; $\mathrm{A}$ : aramid) and two DIVINYCELL core materials with different densities $\left(\rho=0.1,0.2 \mathrm{~g} / \mathrm{cm}^{3}\right)$ were considered. These sandwich panels were fabricated by IHI craft/Japan. The sandwich specimen were cut from a $540 \mathrm{~mm} \times 450$ mm sandwich panel using a diamond coated wheel saw. The dimension of specimen are $90 \mathrm{~mm} \times 45 \mathrm{~mm}$. The average thickness of specimen is $13.9 \mathrm{~mm}$. For the reason of simplicity, in following article, sandwich panels with laminated facesheets MAM, MCM, MRM are named MAM, MCM, MRM, respectively.

\subsection{Instrumented impact test system}

An instrument drop weight impactor tower with adjustable impactor was used in the impact test. The illustration of the drop weight tower is shown in Fig. 1. The tower consists of two vertical steel rods mounted on a heavy steel base. Attached to the vertical steel rods is an aluminum beam cross-bar with idealized frictionless sliding bearings inside. A $19 \mathrm{~mm}$ diameter cylindrical impactor and a PCB200A05 force transducer were mounted on the bottom side of the cross-bar. So, the impact force history can be acquired and recorded by HP5183U Data Recorder (sampling rate up to $16 \mathrm{MHz}$ ). In addition, a simply supported fixure with span of 60 mm was fixed on the steel base. The block diagram of instrumented impact test system is shown in Fig. 2.

For the uniform impact loading across the width of the specimen, a particular simply supported fixture with the ability of making fine adjustments for a uniform contact surface was designed. The adjustment of the fixture was performed before every impact testing and until no light passed through the gap between the specimen and the impactor.

\section{Experimental Results and Discussion}

\subsection{Core density $\rho=0.1 \mathrm{~g} / \mathrm{cm}^{3}$}

The total mass of the impactor is $1.52 \mathrm{~kg}$. Experimental results show that impact behaviors of MAM, MCM, MRM are almost the same, so only the detailed results

Table 1 Fabric materials

\begin{tabular}{ccc}
\hline Fiber & Fabric style & Fabric weight $\left(\mathrm{g} / \mathrm{m}^{2}\right)$ \\
\hline REM 300-65 Glass mat ( M ) & chopped & 300 \\
REM 500-M Glass roving ( R ) & plain woven & 570 \\
Co 6644B Carbon ( C ) & plain woven & 300 \\
T-900 Aramid ( A ) & plain woven & 317 \\
\hline
\end{tabular}

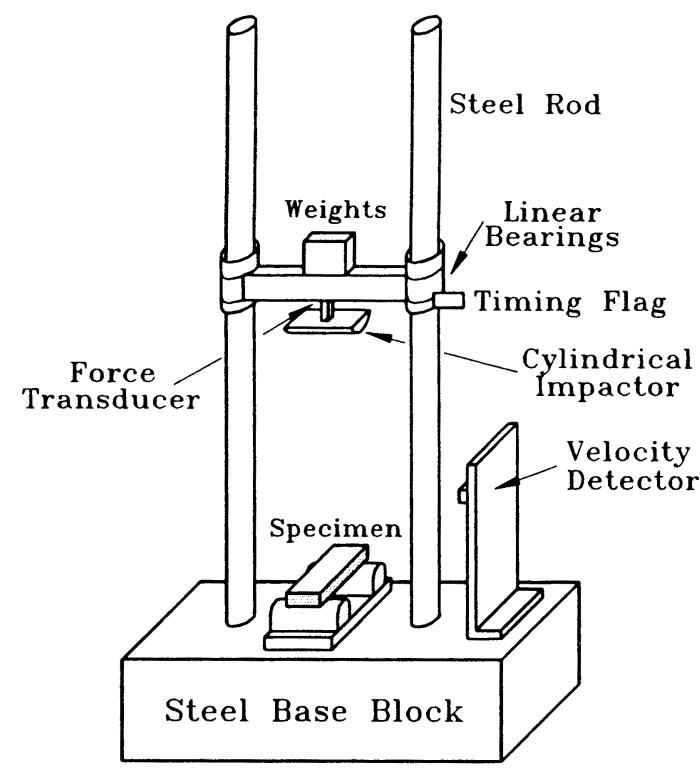

Fig. 1 Drop weight tower



Fig. 2 The block diagram of instrumented test system

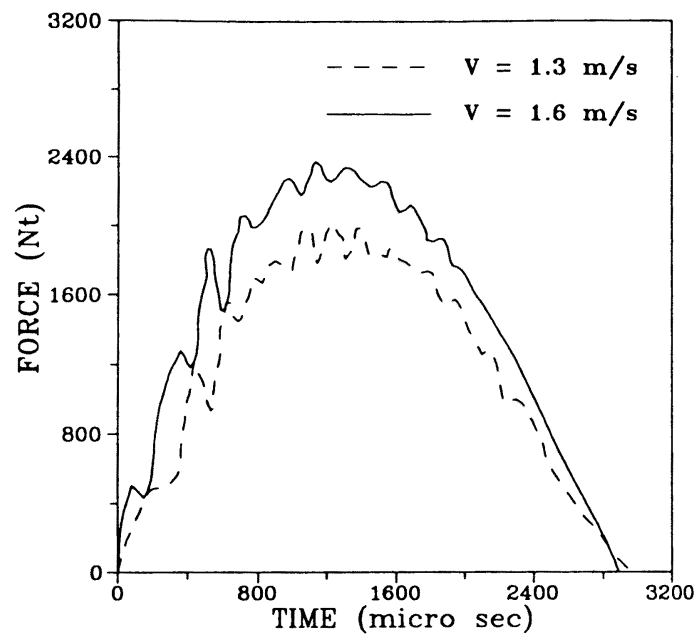

Fig. 3 Comparison of impact force histories at the impact velocity of $1.3,1.6 \mathrm{~m} / \mathrm{s}$ (MAM, core density 0.1 ) 
of MAM are presented and discussed.

Fig. 3 shows the impact force histories at the impact velocity of 1.3 and $1.6 \mathrm{~m} / \mathrm{s}$. Under the range of these impact velocities, there is no damage occurred in sandwich panels. It can be seen from Fig. 3 that the contact duration is almost independent of the impact velocity, and the faster the impact velocity, the larger impact force. When the impact velocity is increased to about 2 . $0 \mathrm{~m} / \mathrm{s}$, the impact force history then has an obvious jump at $1000 \mu$ s (as shown in Fig. 4). An impact crack along the 45 degree direction in core material is found in the region of $10 \mathrm{~mm}$ to $20 \mathrm{~mm}$ away from the impact point, but no fracture in facesheet is found. As the impact velocity increases, the crack will extend to the face-core interfaces, and induce the delamination along the interfaces. The impact damage is shown in Fig. 5.

One of the objectives of the impact experiment is to

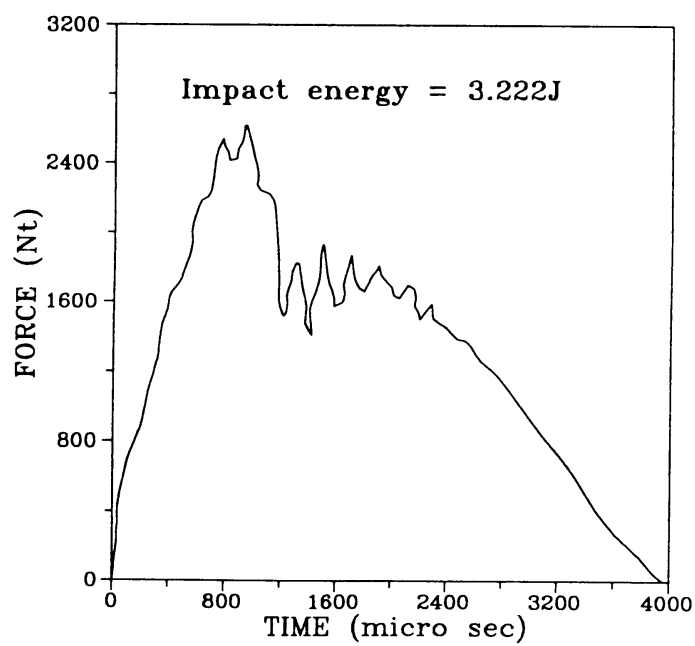

Fig. 4 The impact force history of sandwich panel (MAM, core density 0.1 )

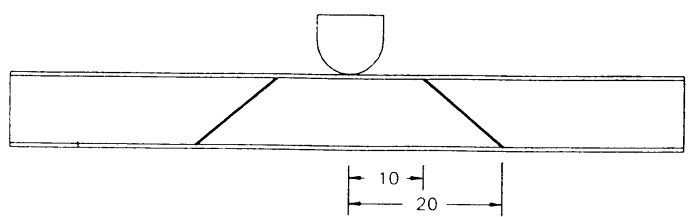

(a)

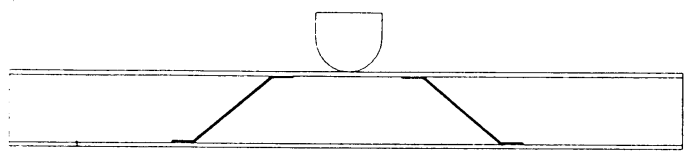

(b)

Fig. 5 (a) crack in core material (b) delamination on face-core interface due to crack in core material investigate the impact resistance of composite sandwich panels. Traditionally, impact resistance has been defined as the ability of a material to absorb energy during fracture. The higher the energy absorption, the tougher the material. However, it is impossible to measure the energy absorption of sandwich panels directly, but if it is assumed that energy loss is almost zero during the impact process, the energy absorbed by the sandwch panel is approximately equal to the loss of kinetic energy of the impactor ${ }^{5)}$.

In order to know the variance of kinetic energy of the impactor, it is necessary to obtain the velocity of the impactor during impact. In this study, the impactor is assumed as a rigid body, then through the ImpulseMomentum relationship, the velocity of the impactor, at
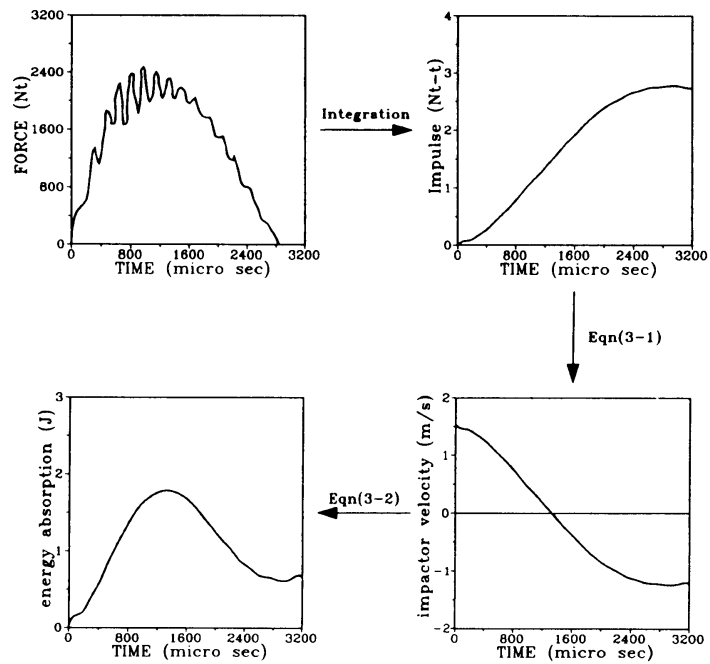

Fig. 6 The procedure of calculating the energy absorption history

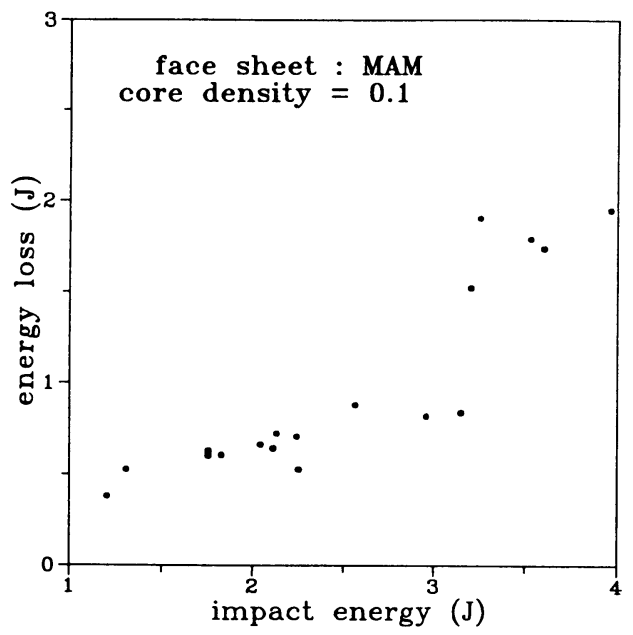

Fig. 7 The impact energy vs. energy loss relationship 
various instants of time, is given

$$
V(t)=V_{i}-\frac{1}{m} \int_{0}^{t} F d t
$$

where $V(t)$ and $V_{i}$ represent the velocity of impactor and initial velocity, respectively. $m$ is the mass of the impactor, and $F$ is the impact force measured in the impact test.

The kinetic energy loss of the impactor is then given by

$$
E(t)=\frac{1}{2} m V_{i}^{2}-\frac{1}{2} m V(t)^{2}
$$

An example of the procedure of calculating the energy absorption history is shown in Fig. 6 .

The impact energy vs. energy loss relationship is shown in Fig. 7. From Fig. 7, the energy loss jump can

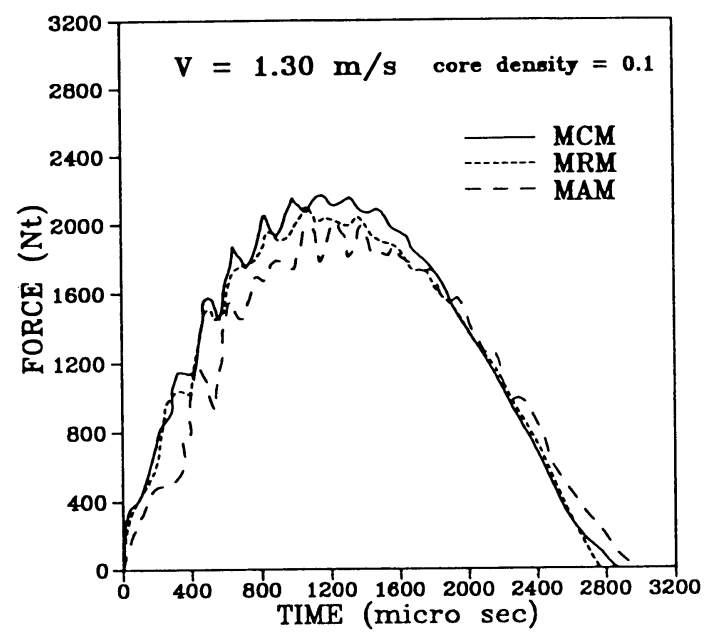

(a)

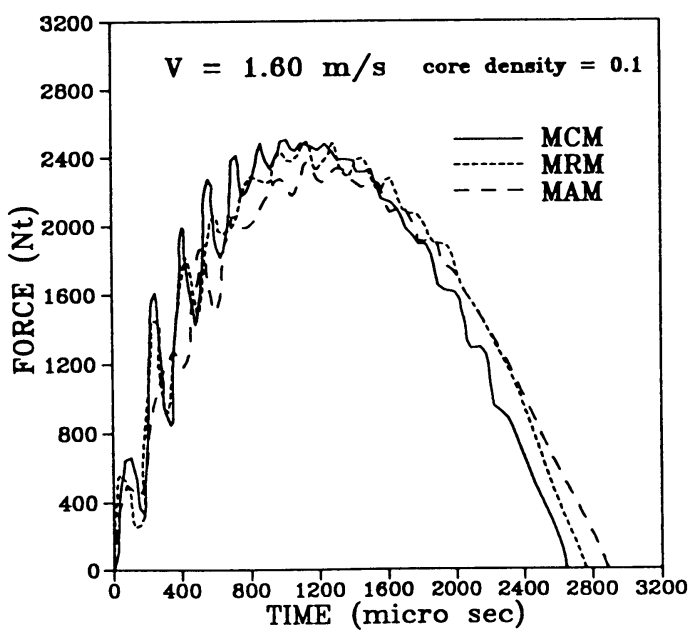

(b)

Fig. 8 Comparison of impact force histories (a ) the impact velocity $1.3 \mathrm{~m} / \mathrm{s}$ ( b ) the impact velocity $1.6 \mathrm{~m} / \mathrm{s}$ (core density 0.1 ) be found when the impact energy reaches about 3.2 Joule. Through the fracture inspection on specimen, it is found that under the impact energy level of 2.977 Joule, there is no damage on sandwich panel, but when the energy level is up to 3.22 Joule (critical impact energy), crack in core material is found. So, it may be concluded that the energy loss jump is due to the shear crack in core mateial.

\section{2 Comparison of MAM, MCM, MRM, core den- sity $\rho=0.1 \mathrm{~g} / \mathrm{cm}^{3}$}

Impact force histories of MAM, MCM, MRM at different impact velocity are shown in Fig. 8. It can be seen that the impact force histories of these sandwich panels are nearly the same. The critical impact energy is shown in Table 2. It should be noted that the difference of these energy is small. From the results of Table 2, It can be concluded that MAM are the best one for resisting the impact, and MCM are the worst.

\section{3 core density $\rho=0.2 \mathrm{~g} / \mathrm{cm}^{3}$}

The total mass of the impactor is $2.018 \mathrm{~kg}$. Experimental results also show that the impact behaviors of MAM, MCM, MRM are almost the same. Just so, only the results of MAM are presented for the reason of simplicity. The experimental results show that there is no damage in the specimen as impact energy lower than 4 Jouel. With the increase of impact energy, the core material will be crushed away under the impact point, but, while the impact force curve has no any obvious jump, the curve just becomes smooth near the ampli-

Table 2 The critical impact energy of composite sandwich (core density $\rho=0.1 \mathrm{~g} / \mathrm{cm}^{3}$ )

\begin{tabular}{cc}
\hline Facesheet & Critical impact energy \\
\hline MAM & $2.97 \mathrm{~J} \sim 3.22 \mathrm{~J}$ \\
MCM & $2.60 \mathrm{~J} \sim 2.86 \mathrm{~J}$ \\
MRM & $2.83 \mathrm{~J} \sim 3.11 \mathrm{~J}$ \\
\hline
\end{tabular}

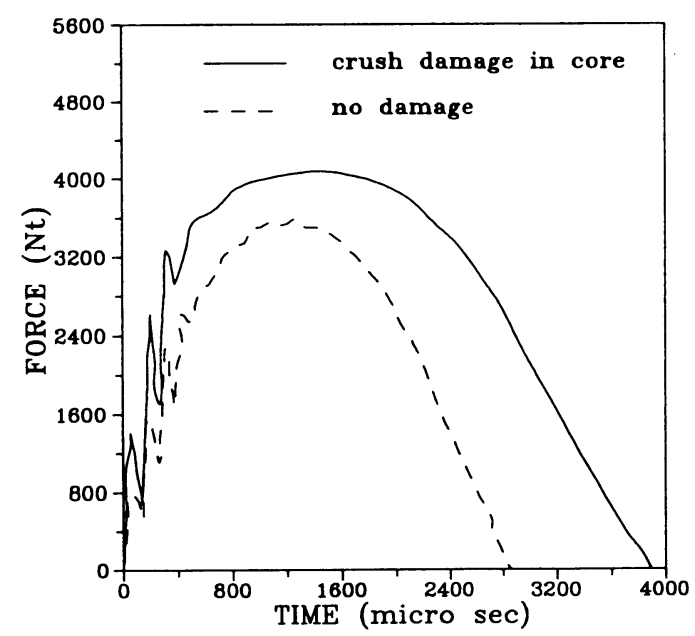

Fig. 9 Comparison of impact force histories (MAM, core density 0.2 ) 
tude of impact force and the shape of the curve is less symmetric (as shown in Fig. 9). As energy level increases, apart from the crush zone area increase, there are matrix crackings found in the lowest lamina (Mat layer) of the top facesheet.

\section{4 Comparison of MAM, MCM, MRM, core den-} sity $\rho=0.2 \mathrm{~g} / \mathrm{cm}^{3}$

The impact force histories of MAM, MCM, MRM at the impact velocity of 1.5 and $1.75 \mathrm{~m} / \mathrm{s}$ are shown in Fig. 10. It can be seen that the impact force histories are nearly the same. The failure modes of these specimen at the impact energy levels of $4 \mathrm{~J}, 5 \mathrm{~J}, 6 \mathrm{~J}, 7 \mathrm{~J}$, are drawn in Figs. 11-13.

From Figs. 11-13, no damage is found on MAM as the energy level lower than 4 Joule. When the energy level

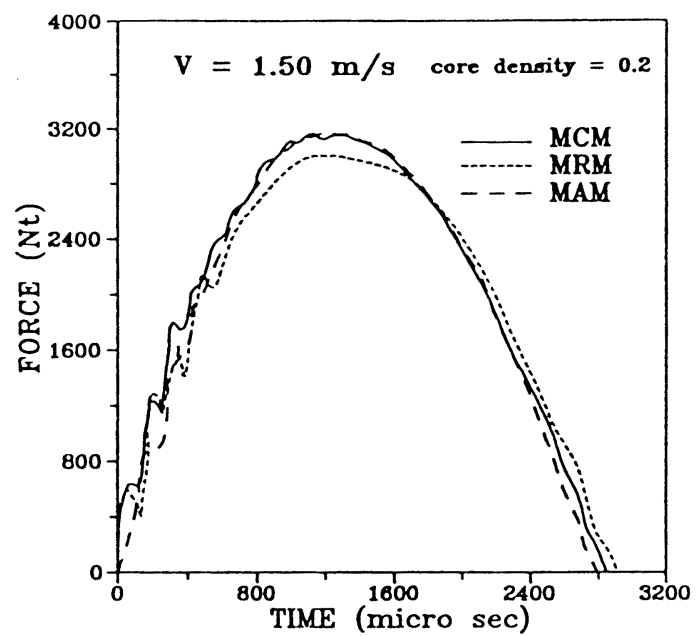

(a)

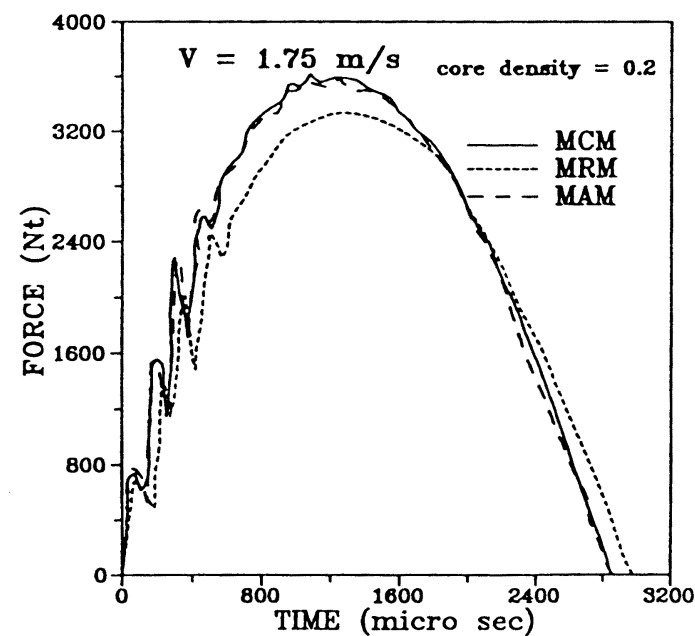

(b)

Fig. 10 Comparison of impact force histories (a) the impact velocity $1.5 \mathrm{~m} / \mathrm{s}$ (b) the impact velocity $1.75 \mathrm{~m} / \mathrm{s}$ (core density 0.2 ) no damage in core

crush damage in core

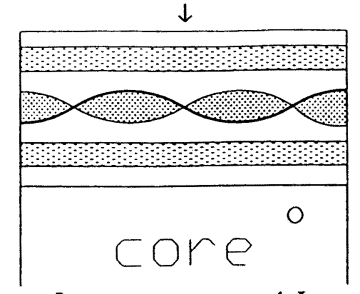

Impact energy $=4 \mathrm{~J}$

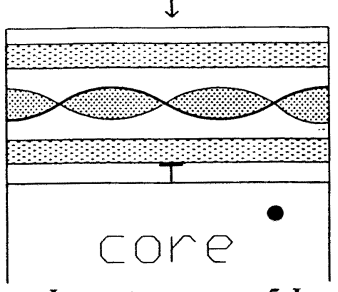

Impact energy $=5 \mathrm{~J}$

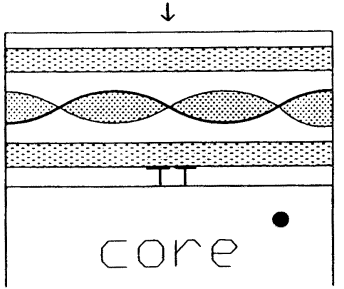

Impact energy $=6 \mathrm{~J}$

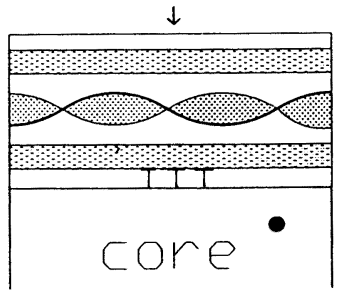

Impact energy $=7 \mathrm{~J}$
Fig. 11 Illustration of failure mode (MAM, core density 0.2 )

no damage in core

- crush damage in core


Impact energy $=4 \mathrm{~J}$

Impact energy $=5 \mathrm{~J}$

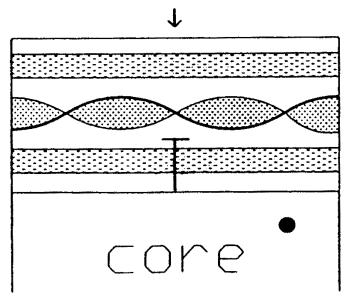

Impact energy $=6 \mathrm{~J}$

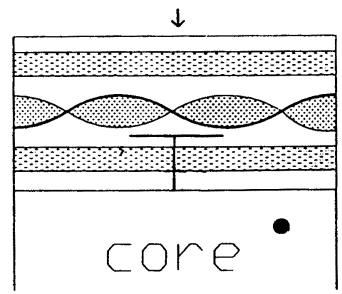

Impact energy $=7 \mathrm{~J}$

Fig. 12 Illustration of failure mode (MCM, core density 0.2 ) 
no damage in core

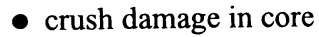

$\downarrow$

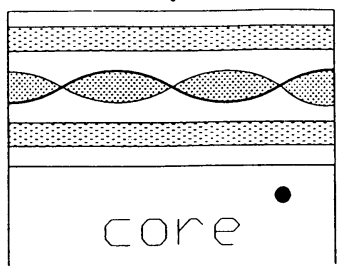

Impact energy $=4 \mathrm{~J}$

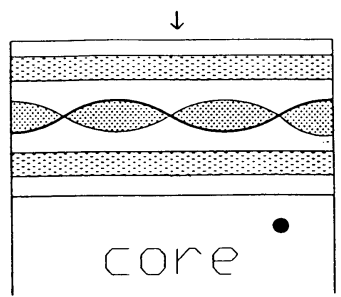

Impact energy $=5 \mathrm{~J}$

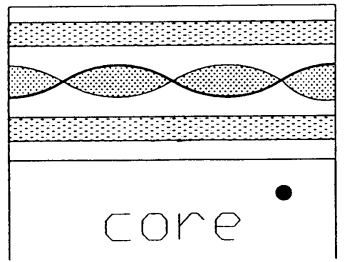

Impact energy $=6 \mathrm{~J}$

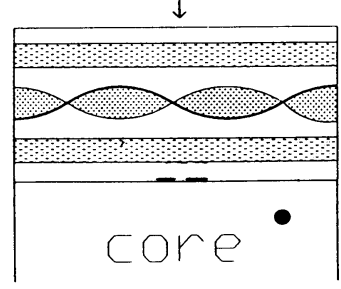

Impact energy $=7 \mathrm{~J}$
Fig. 13 Illustration of failure mode (MRM, core density 0.2 )

is 5 Joule, there are both crush in core material and matrix crackings in the lowest lamina of the top facesheet. With the increase of impact energy, the core damage area increases, and the damage in top facesheet is also more serious. As for MCM, when the energy level is 4 Joule, matrix crackings in top facesheet occur, but core material has no damage. It is worth noting that the fiber breakage in the lowest lamina (Mat Layer) of top facesheet is found when the impact energy level is up to 6 Joule. When it comes to MRM, crush damage in core under impact point has occurred at the energy level of 4 Joule, but no facesheets damage found. However, as the impact energy increases, the matrix cracks in top facesheets are less serious than those of the other two sandwich panels. According to foregoing results, it can be concluded that the MAM have the better impact resistance performance.

\section{5 Comparison of core density $\rho=0.1,0.2 \mathrm{~g} / \mathrm{cm}^{3}$}

Referring to Fig. 14, it can be seen that the impact force histories of MAM, MCM, MRM fit each other very well under the same core density. Also, it can be found that the higher core density produces the larger impact force amplitude and shorter contact duration. The failure modes of sandwich panels with core density 0.1 , under the impact energy ranging from 1 Joule to 4 Joule, are shear crack in core material generally, but no damage in top facesheet. Under the impact energy ranging from 2 Joule to 7 Joule, the failure modes of sandwich panels with core density 0.2 are crush in foam



Fig. 14 Comparison of impact force histories

core and matrix cracking in top facesheet under the impact point. The critical impact energy of sandwich panels with core density 0.2 is higher than those with core density 0.1 , therefore sandwich structures with core density 0.2 have the better impact resistance.

From foregoing results mentioned, the impact behaviors of the six kinds of sandwich structures in this study are mainly controlled by core density.

\section{Numerical Results and Discussion}

\section{1 Impact response analysis}

The dynamic responses of the sandwich panels are also performed by the finite element software ABAQUS. Because of the line load conditions, the sandwich panels impacted by a cylindrical impactor can be modeled as a 2-D plane strain problem. A four-node, plane strain element with two degrees of freedom at each node is used. The impactor is assumed as a rigid body.

ABAQUS provides a family of contact elements that allow the modeling of contact between a deforming body and an arbitrarily shaped rigid body. At each intergration point these elements construct a measure of overclosure (penetration of the point on the surface of the deforming body into the rigid surface). Using these kinematic constraints, together with appropriate Lagrange multiplier techniques, one surface may not penetrate into the other, while the surface contact theory is introduced ${ }^{6}$. Once the contact pressure is calculated out, then the stress contour of the whole sandwich panel can be obtained. In this study, contact element IRS21 is used.

The finite element mesh used in sandwich structures analysis is shown in Fig. 15. Because of the material and geometric symmetry, only one-half region with symmetric conditions is analyzed. A summary of the material properties of fabric laminates and core material is given in Table 3. 


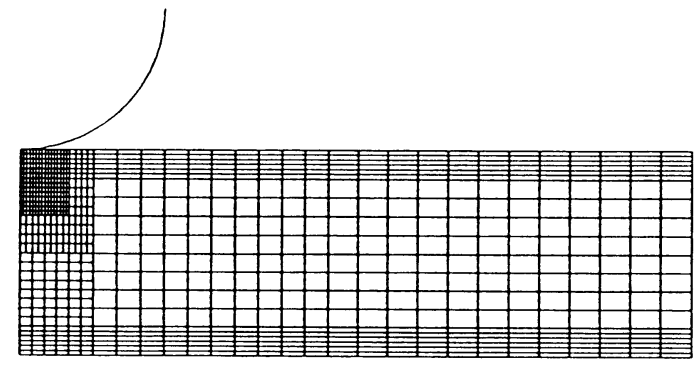

Fig. 15 Finite element mesh of one-half region of sandwich panel

Table 3 Material constants used in numerical analysis (a) DIVINYCELL core material (b) facesheet

(a) DIVINYCELL core material

\begin{tabular}{c|c|c}
\hline $\begin{array}{c}\text { Density } \\
\left(\mathrm{g} / \mathrm{cm}^{3}\right)\end{array}$ & $\begin{array}{c}\text { Compressive } \\
\text { modulus (MPa) }\end{array}$ & $\begin{array}{c}\text { Shear } \\
\text { Modulus (MPa) }\end{array}$ \\
\hline 0.1 & 120 & 45 \\
0.2 & 230 & 80 \\
\hline
\end{tabular}

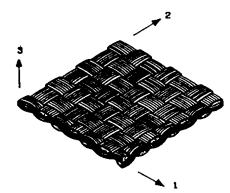

(b) Facesheet

\begin{tabular}{c|c|c|c|c|c|c|c|c|c|c}
\hline \multirow{2}{*}{ Lamina } & \multicolumn{3}{|c|}{$\begin{array}{c}\text { Modulus of elasticity } \\
(\mathrm{GPa})\end{array}$} & \multicolumn{2}{c|}{$\begin{array}{c}\text { Modulus of elasticity } \\
\text { in shear }(\mathrm{GPa})\end{array}$} & \multicolumn{2}{c|}{$\begin{array}{c}\text { Poisson's } \\
\text { ratio }\end{array}$} & $\begin{array}{c}\text { Density } \\
\left(\mathrm{kg} / \mathrm{m}^{3}\right)\end{array}$ \\
\cline { 2 - 11 } & $\mathrm{E}_{11}$ & $\mathrm{E}_{22}$ & $\mathrm{E}_{33}$ & $\mathrm{G}_{12}$ & $\mathrm{G}_{13}$ & $\mathrm{G}_{23}$ & $\mathrm{v}_{12}$ & $\mathrm{v}_{13}$ & $\mathrm{v}_{23}$ & $\rho$ \\
\hline $\mathrm{M}$ & $8.88^{*}$ & $8.88^{*}$ & $8.814^{\circ}$ & $3.39^{*}$ & $3.39^{*}$ & $3.39^{*}$ & $0.31^{*}$ & $0.3^{*}$ & $0.3^{\circ}$ & $1430^{*}$ \\
$\mathrm{R}$ & $18.5^{*}$ & $18.5^{*}$ & $8.814^{*}$ & $4.81^{*}$ & $3.04^{*}$ & $3.04^{*}$ & $0.05^{*}$ & $0.3^{\circ}$ & $0.3^{\circ}$ & $1690^{*}$ \\
$\mathrm{C}$ & $43^{*}$ & $43^{*}$ & $8.814^{*}$ & $2.26^{*}$ & $1.43^{*}$ & $1.43^{*}$ & $0.08^{*}$ & $0.3^{*}$ & $0.3^{*}$ & $1300^{*}$ \\
$\mathrm{~A}$ & $25^{*}$ & $25^{*}$ & $8.814^{*}$ & $1.96^{*}$ & $1.23^{*}$ & $1.23^{*}$ & $0.124^{*}$ & $0.3^{*}$ & $0.3^{*}$ & $1290^{*}$ \\
\hline
\end{tabular}

\# : Ref. 7), 8)

*: estimated value

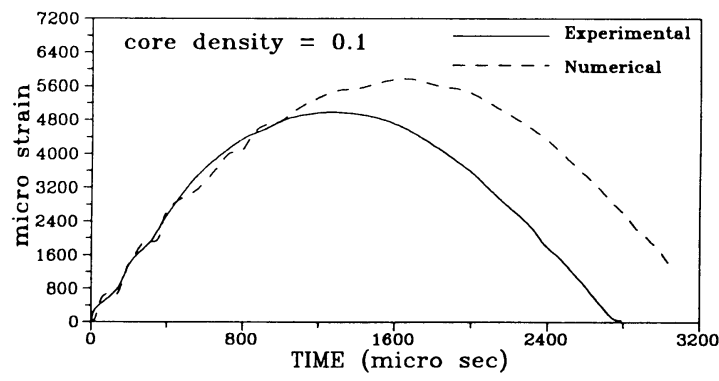

(a)

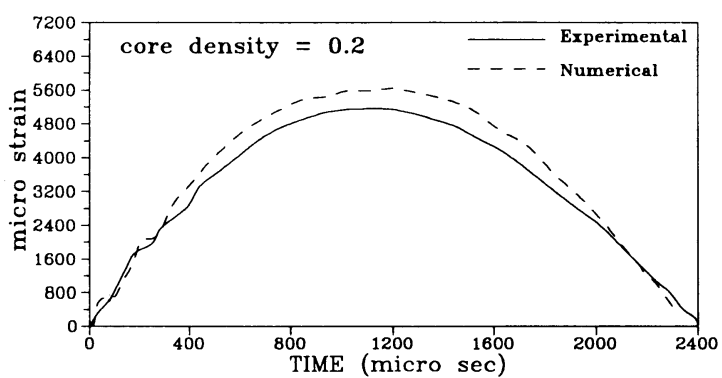

(b)

Fig. 16 Comparison of strain histories (MAM) (a) core density 0.1 ( b ) core density 0.2

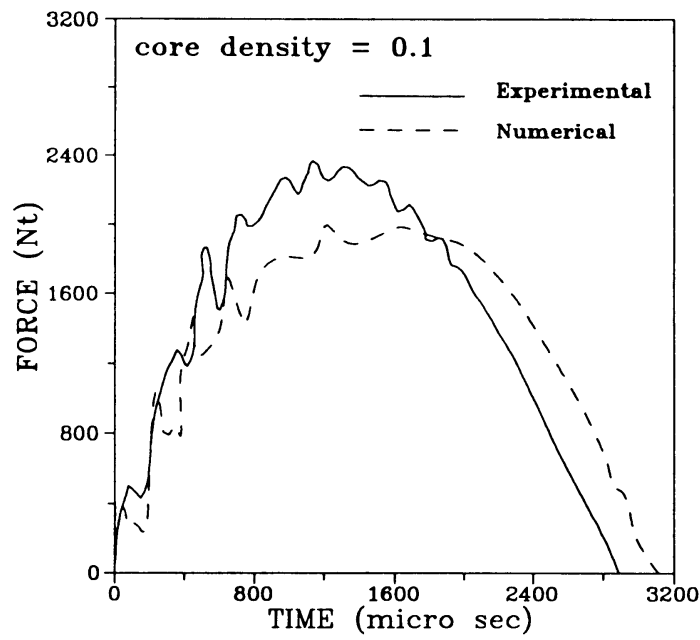

(a)

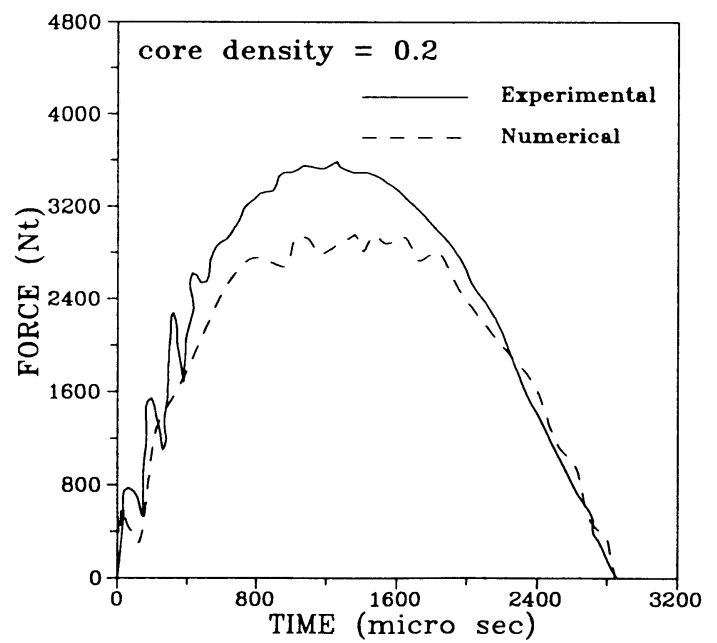

(b)

Fig. 17 Comparison of impact force histories (MAM) (a) core density 0.1 (b) core density 0.2

The computed strain histories of MAM at the center on the bottom face of sandwich panels are shown in Fig. 16 , and compared to the strain obtained from the experiment. From Fig. 16 ( a ), It can be seen that the experimental and numerical results match very well before $800 \mu \mathrm{s}$, but the magnitude of the computed peak strain exceeds that measured. In Fig. 16 ( b ), the experimental results and numerical solution fit each other very well. In Fig. 17, the comparision of the computed and experimental impact force histories are also presented. As can be seen in Fig. 17, the shape of computed impact force history is nearly the same as that recorded in the experiment, but the magnitude of the computed peak force is less than that measured. As mentioned before, the impact responses are dominated by core material, so 
the understanding of core material behavior (especially the plastic behavior) will decide if the numerical results are in good agreement with the experimental results. Unfortunately, the DIVINYCELL core material supplier didn't provide sufficient material properties which can quantitatively describe the plastic behavior of foam core. So, lack of knowledge on core material behavior is the reason for the discrepancy between numerical solution and experimental results. Another possible reason for the discrepancy may be attributed to neglecting the effect of strain rate.

\section{2 Stress analysis}

The maximum stress criterion was used to analyze the initial fracture of sandwich structures. For the reason of simplicity, Only the stress contours of MAM are demostrated. Fig. 18 show the normalized stress contours $\sigma_{11}, \tau_{\max }, \sigma_{22}$ of sandwich panels with core density 0.1 at the impact velocity of $1.5 \mathrm{~m} / \mathrm{s}$. The normalized stress is defined as stress being divided by the strength of material. From the results of numerical stress analysis, the in-plane normal stress distribution of facesheet is the "local bending" form, that is, the stress

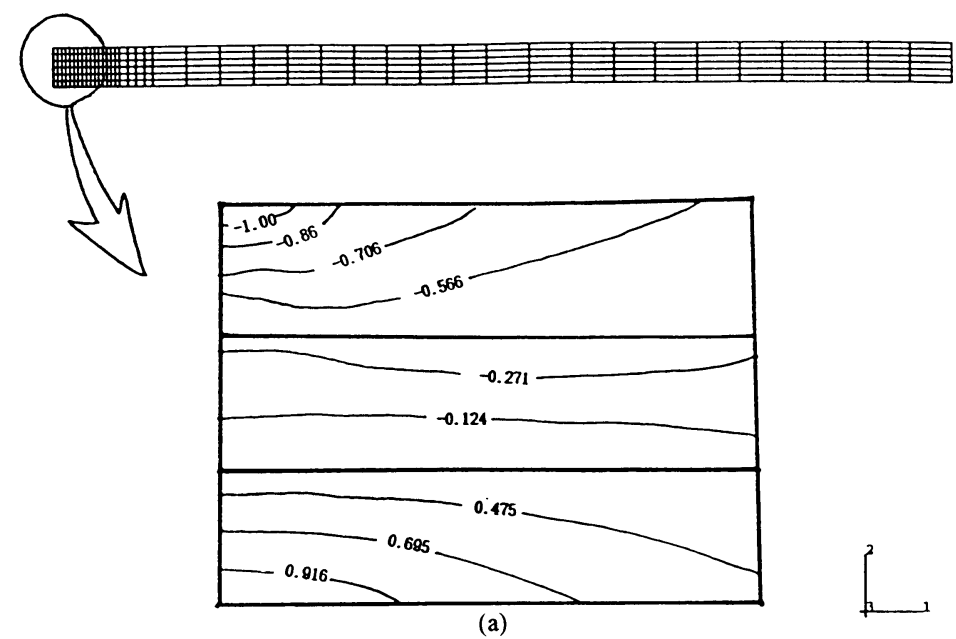

$\downarrow$ Impact point

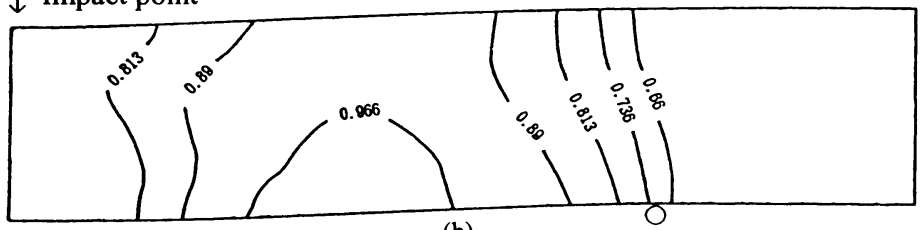

(b)

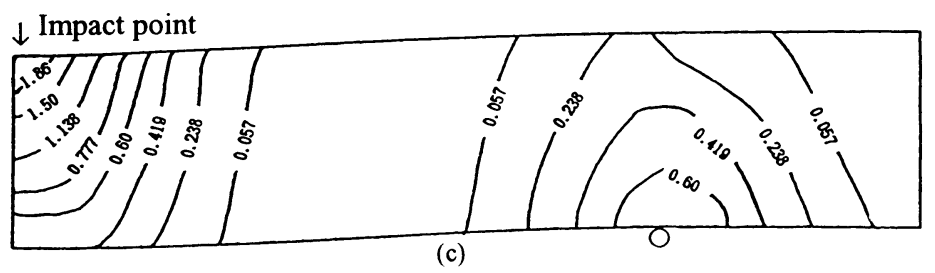

Fig. 18 Normalized stress contours (a) in-plane normal stress $\sigma_{11}$ in facesheet (b) maximum shear stress $\tau_{\max }$ in core material (c) outplane compressive stress $\sigma_{22}$ in core material ( MAM, core density 0.1 , impact velocity $1.5 \mathrm{~m} / \mathrm{s}$ ) 
in the uppermost lamina of facesheet is compressive but tensile in the lowest lamina. In Fig. 18 (a), it can be seen that it tends to in-plane fracture occurred in the uppermost lamina of facesheet due to compressive stress, but in-plane fracture occurred in the lowest lamina due to tensile stress.

In Fig. 18 ( b ), the maximum normalized shear stress of 0.966 exists in a region that ranges approximately from $11.2 \mathrm{~mm}$ to $22.5 \mathrm{~mm}$ away from the impact point. This computed region compares fairly well with the observed region of crack damage in the foam core. Similarly, the normalized out-plane compressive stress contour can be obtained in the same way. From the results of Fig. 18 (c), there should be out-plane compressive fracture in core material, however, this fracture phenomenon hasn't been found obviously by visual observation on specimen. The reasons for this discrepancy are needed to further investigate, which may be owing to the errors in numerical analysis, inaccurate strength values, or local compressive damage in core material being unable to be inspected out only by visual observation.

As for core density 0.2 , the normalized stress contours at the impact velocity of $1.93 \mathrm{~m} / \mathrm{s}$ are shown inFig. 19 .

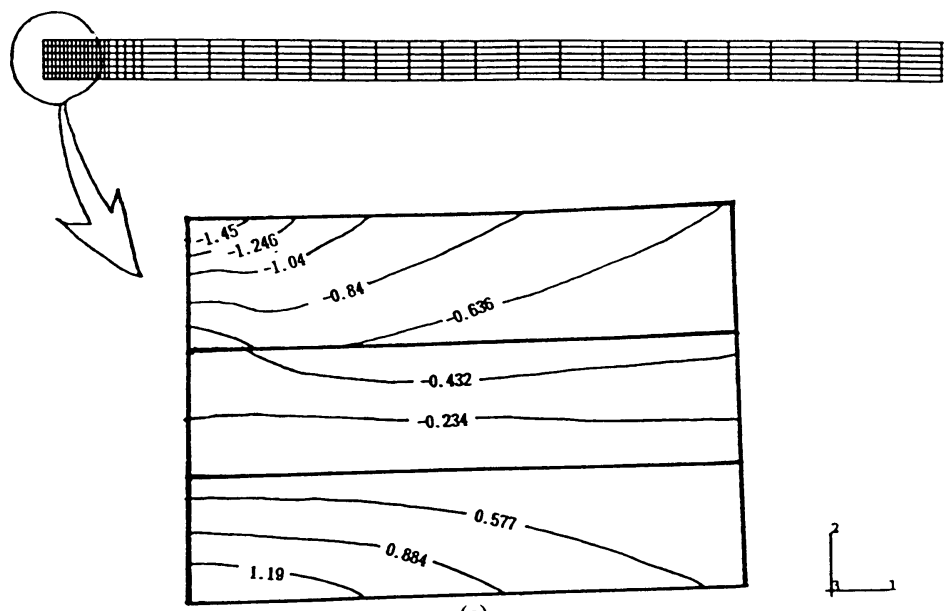

(a)

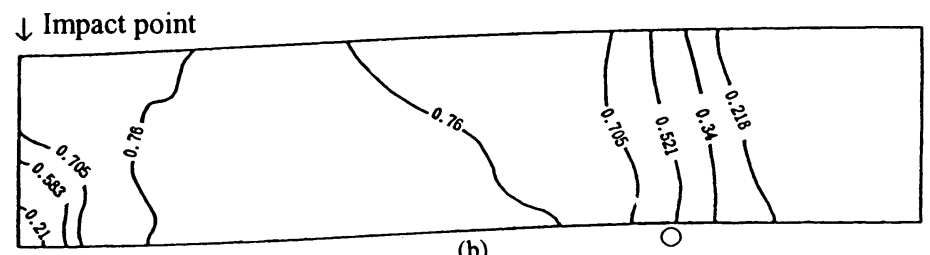

(b)

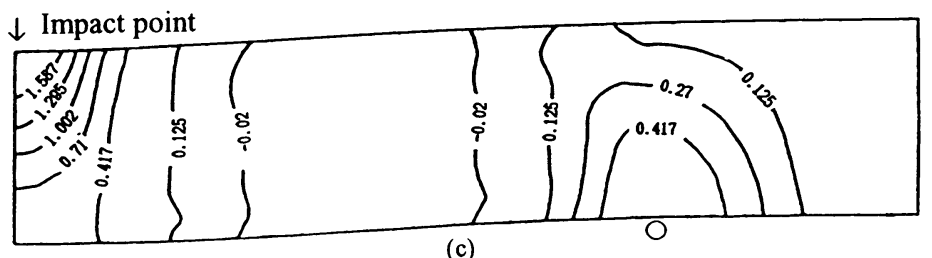

(c)

Fig. 19 Normalized stress contours (a) in-plane normal stress $\sigma_{11}$ in facesheet (b) maximum shear stress $\tau_{\max }$ in core material (c) outplane compressive stress $\sigma_{22}$ in core material (MAM, core density 0.2 , impact velocity 1.93 $\mathrm{m} / \mathrm{s}$ ) 
Fig. 19 (a) indicates that the compressive and tensile fracture will occur in the uppermost and lowest lamina of facesheet, respectively. However, there is no damage found in facesheet from experimental results. When the impact velocity is more than $2 \mathrm{~m} / \mathrm{s}$, matrix crackings as well as fiber breakage due to tensile stress are really found in the lowest lamina, but there is still no compressive fracture occurred in the uppermost lamina. In Fig. 19 (b), it can be seen that the range of maximum shear stress is the same as that of core density 0.1 , but the value of normalized shear stress is smaller (about 0.76 ). From the experimental results, when the impact velocity is over $2 \mathrm{~m} / \mathrm{s}$, no shear crack being found in foam core, but crush in foam core exists under the impact point. Just as shown in Fig. 19 (c), the value of outplane compressive stress near the impact point is truly higher. From the discussion before, the results of numerical analysis can't predict or explain the fracture mechanism very exactly in general. The main reasons might come from material constants, strength, and material behavior of foam core being not guaranteed. Therefore, how to obtain the material properties more accurately by material tests is the problem needed to slove in the furture.

\section{Conclusions}

The dynamic responses of six kinds of sandwich panels used in ship structures under low-velocity impact are investigated experimentally and numerically. In experimental analysis, impact behavior, including impact force history, impact resistance and fracture phenomena are presented. It is found that the impact behavior is mainly controlled by core density, the higher the core density is, the better the impact resistance performance is. Generally, sandwich panels with MAM facesheet have the best impact resistance. In failure mode, sandwich structures with core density 0.1 under the low impact energy tend to have shear crack in core material, but crush in foam core and matrix crackings in facesheet under the impact point for sandwich panels with core density 0.2 .
In numerical analysis, the impactor is assumed as a rigid body, and a 2-D plane strain model is used. The impact responses such as impact force and strain histories are compared with the experimental data. From the comparison, it is evident that the approach using kinematic constraints, together with Lagrange multiplier technique performs well in the analysis of dynamic response.

\section{Acknowledgement}

This work was supported by the National Science Council, Republic of China, under the Grant No. NSC 820401-E-002-172.

\section{References}

1) Michael L. Bernard and Paul A. Lagace, "Impact Resistance of Composite Sandwich Plates", Journal of Reinforced Plastics and Composites, Vol. 8, pp. 432-445, 1989.

2) W. K. Shin and B. Z. Jang, "Instrumented Impact Testing of Composite Sandwich Panels", Journal of Reinforced Plastics and Composites, Vol. 8, pp. 270-289, 1989.

3) J. A. Nemes and K. E. Simmonds, "Low-velocity Impact Response of Foam Core Sandwich Composites", Journal of Composite Materials, Vol. 26, No. 4, pp. 500-519, 1992.

4) T. M. Tan and C. T. Sun, "Use of Statical Indentation Laws in the Impact Analysis of Laminated Composite Plates", Journal of Applied Mechanics, 52 (1985) 6-12.

5) Peter O. Sjoblom and J. Timothy Hartness, "On Low-Velocity Impact Testing of Composite Materials", Journal of Composite Materials, Vol. 22, pp. 30-52, 1988.

6) ABAQUS Theory Manual, American H. K.S. Corp.

7) Isao Kimpara and Toshio Suzuki, "Impact Damage Analysis of Aramid/Glass Hybrid Laminates", J. Soc. Mat. Sci.,, Japan, Vol. 41, No. 462, pp. 382-388, Mar. 1992.

8）金原勲, 鈴木敏夫, “小型船舶用新素材に関する調査 研究”, 日本小型船舶検査機構, 12, 1992. 